\title{
CONHECIMENTO E CONDUTAS REALIZADAS POR ENFERMEIROS DA ATENÇÃO BÁSICA PERANTE AS SÍNDROMES HIPERTENSIVAS DA GRAVIDEZ - SHG
}

\section{KNOWLEDGE AND CONDUCT BY NURSES OF BASIC ATTENTION AGAINST HYPERTENSIVE SYNDROMES OF PREGNANCY - SHG}

\author{
Edna Ferreira Guimarães NASCIMENTO'1 \\ ednaf_gbi@hotmail.com
}

\author{
Arlete Maria Gomes OLIVEIRA²
}

arlete.oliveira@slmandic.edu.br

Flavia Martão FLÓRIO3

flaviaflorio@yahoo.com

Luciane ZANIN $^{4}$

zaninsouza@yahoo.com.br

\begin{abstract}
RESUMO
Foram avaliados o conhecimento e as condutas dos enfermeiros da Estratégia de Saúde da Família (ESF) perante a Síndrome Hipertensiva da Gravidez (SHG), no município de Guanambi - BA. Estudo descritivo quantitativo, desenvolvido com 25 enfermeiros que atuam ou atuaram na Estratégia de Saúde da família (ESF). Utilizou-se um questionário semiestruturado, autoaplicável, contendo 14 questões relacionadas à identificação do profissional, conduta e conhecimento sobre SHG. Dados foram analisados por meio de tabelas de distribuição de frequências. Houve predominância do gênero feminino $(80,0 \%), 83,4 \%$ tinham mais de 4 anos de formação, 76,0\% atuavam na ESF em média 3 anos e 84,0\% têm especialização. Identificou-se no período de 12 meses que 08 gestantes apresentaram quadro de SHG, destas, 06 tiveram acompanhamento na atenção secundária e 02 permaneceram com atendimento na ESF. Sobre referência e contra-referência, 64\% (16) afirmaram que todas as gestantes continuam as consultas de pré-natal na unidade, $12 \%$ (03) relataram que a maioria das gestantes continuam com atendimento na unidade e 06 (24\%) afirmaram não continuar. Os enfermeiros apresentaram dificuldades em identificar as complicações e consequências para desenvolvimento de SHG em gestantes atendidas na Estratégia Saúde da Família, sendo a maior dificuldade relacionada ao encaminhamento.
\end{abstract}

DESCRITORES: ESTRATÉGIA DA SAÚDE DA FAMÍLIA; GESTANTES; SÍNDROME.

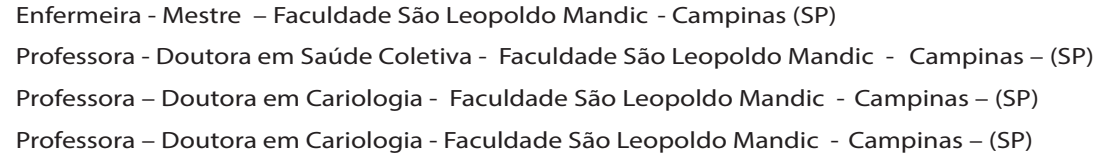


ISSN 1983-5183

\section{ABSTRACT}

Were evaluated the knowledge and behaviors of nurses of the Family Health Strategy (FHS) in relation to the Hypertensive Pregnancy Syndrome (HPS) in the municipality of Guanambi - BA. This is a quantitative descriptive study developed with 25 nurses who work or have worked in the Family Health Strategy (FHS). A semi-structured, self-administered questionnaire containing 14 questions related to the identification of the professional, conduct, knowledge. Data were analyzed by frequency distribution tables. There was a predominance of female gender (80.0\%), 83.4\% had more than 4 years of education, $76.0 \%$ had a 3 -year FHS, and $84.0 \%$ had specialization. It was identified in the 12-month period that 08 pregnant women presented SHG, of these, 06 had follow-up in the secondary care and 02 remained with care in the FHS. Regarding reference and contra-referral, $64 \%$ (16) stated that all pregnant women continued prenatal visits at the unit, $12 \%$ (03) reported that most of the pregnant women still attended the unit and $06(24 \%)$ said not continue. Nurses presented difficulties in identifying complications and consequences for the development of FHS in pregnant women attended in the Family Health Strategy, being the greatest difficulty related to referral.

DESCRIPTORS: FAMILY HEALTH STRATEGY; PREGNANT WOMEN; SYNDROME.

\section{INTRODUÇÃO}

A gestação consiste em um período de mudanças no organismo da mulher, caracterizando um fenômeno fisiológico que deve ser encarado pelas gestantes e equipes de saúde como parte de uma experiência de vida saudável envolvendo mudanças dinâmicas do ponto de vista físico, social e emocional. Entretanto, trata-se de um período limítrofe que pode implicar riscos tanto para a mãe quanto para o feto e há um determinado número de gestantes que, por características particulares, apresentam maior probabilidade de evolução desfavorável, devido a serem portadoras de doenças crônicas e fazerem uso de drogas lícitas e ilícitas?'

No período gestacional as Síndromes Hipertensivas da Gravidez (SHG), que se classificam em Hipertensão crônica, pré-eclâmpsia/eclâmpsia, pré-eclâmpsia sobreposta à hipertensão crônica e hipertensão gestacional, atingem cerca de 6 a 8\% das gestantes, sendo que a mais comum é a Hipertensão Gestacional². Em meio às complicações da gestação, as Síndromes Hipertensivas da Gravidez (SHG) referemse a uma das complicações que ocorre no período gestacional, podendo se instalar com um quadro leve ou na forma mais grave, geralmente evoluindo para uma eclâmpsia ou síndrome de Hemólise e Alteração das Provas da Função Hepática com Diminuição dos Números de Plaquetas (HELLP), responsáveis por casos de morbimortalidade materna e perinatal. $O$ diagnóstico precoce possibilita um melhor prognóstico materno e perinatal, e consequentemente reduz a mortalidade ocasionada pelas Síndromes Hipertensivas da Gravidez ${ }^{3}$.

Segundo a Organização Mundial da Saúde as perspectivas de avanço para o cumprimento das metas referentes à mortalidade materna era de reduzir $75 \%$ a taxa mortalidade materna até 2015. Entretanto o Brasil não atingiu essa meta, consegui reduzir apenas em $52 \%$ o número de óbitos maternos 4 .

De acordo com o Ministério da Saúde, a Síndrome Hipertensiva da Gravidez caracteriza-se pela presença de pressão arterial sistólica maior ou igual a $140 \mathrm{~mm} \mathrm{Hg}$ e pressão diastólica maior ou igual $90 \mathrm{~mm} \mathrm{Hg}$, edema, proteinúria, sinais estes que ocorrem após a 20ª semana de gestação1. 
NASCIMENTO EFG, OLIVEIRA AMG, FLÓRIO FM, ZANIN L. Conhecimento e condutas realizadas por enfermeiros da atenção básica perante as síndromes hipertensivas da gravidez - SHG. Rev. Odontol. Univ. Cid. São Paulo 2019 jan-mar; 31(1): 6-16

ISSN 1983-5183

Durante a assistência do pré-natal o enfermeiro deve fazer uma avaliação dinâmica da gestante em busca de situações de risco. É importante destacar que é dever do profissional saber identificar problemas, de forma a atuar com segurança, tanto para a gestante quanto para o feto, visando diminuir e prevenir complicações, por meio de uma assistência de qualidade ${ }^{5}$. Quando o profissional enfermeiro reconhece uma gestação de alto risco ao identificar os sinais da doença, ele deve seguir uma linha de cuidados pressupondo um acompanhamento por parte das equipes da Estratégia da Saúde da Família (ESF), e posterior encaminhamento para os serviços especializados ${ }^{1}$.

O diagnóstico da SHG deve ser o mais precoce possível, objetivando impedir a sua evolução. Gestantes classificadas com maior risco de desenvolver a doença devem ser submetidas às consultas de pré-natal com mais frequência, sendo importante aferir os valores de pressão arterial, proteinúria, ganho ponderal e dosagem sérica de ácido úrico e ureia/creatinina com frequência ${ }^{6}$. Esse procedimento interfere tanto na redução da mortalidade materna como em possíveis complicações ocasionadas por tais patologias. Além disso, é fundamental que se tenha acompanhamento adequado e assistência de qualidade?

Nesse contexto, o presente estudo avaliou o conhecimento e conduta de enfermeiros da Estratégia de Saúde da Família (ESF) perante a Síndrome Hipertensiva da Gravidez (SHG), com o intuito de contribuir com a identificação de situações que necessitam de implementação e melhorias, o que poderá impactar positivamente na qualidade dos serviços prestados às gestantes com SHG.

\section{MATERIAIS E MÉTODOS}

Pesquisa exploratória descritiva quantitativa, aprovada pelo Comitê de Ética em Pesquisa da Faculdade São Leopoldo Mandic - Campinas - SP - Protocolo: 4445521520000537.0 estudo teve início após assinatura do Termo de Consentimento Livre e Esclarecido (TCLE) pelos voluntários. A pesquisa se desenvolveu em um município situado na mesorregião do Centro Sul Baiano, distante 796 quilômetros a sudoeste da Capital. O município possui um IDH de 0,673 (IBGE, 2015). O sistema de saúde na atenção básica é composto de 19 Unidades de Saúde da Família (ESF), 02 Unidades Básicas de Saúde (UBS) e 01 Unidade de atendimento de alto risco a gestante no Hospital Regional de média complexidade.

A amostra de conveniência foi composta por todos os 25 enfermeiros que atuavam na Estratégia de Saúde da Família (ESF) do município no período de 2015 a 2016. Os dados foram coletados por meio de um questionário semiestruturado, elaborado com a colaboração de um médico especialista em ginecologia e obstetrícia e no Manual do Ministério da Saúde' que estabelece a definição, classificação e conduta perante as Síndromes Hipertensivas da Gravidez (SHG). Foram inseridas junto a esse questionário perguntas não relacionadas às Síndromes Hipertensivas da Gravidez, com sinais e sintomas semelhantes, com o objetivo de verificar o conhecimento e a conduta dos profissionais, referente ao detalhamento na anamnese para o diagnóstico das Síndromes.

O questionário é composto por 04 blocos: a) Identificação do profissional - questões $01,02,03$, 04 e 05 (abordando data de preenchimento do questionário, sexo, tempo em que concluiu a graduação em enfermagem, especialização realizada, tempo de atuação na SHG, quantas gestantes realizavam o acompanhamento na atenção secundária e quantas foram as consultas do Pré-natal na unidade); b) Conduta perante o diagnóstico - questões 06,10 e 12 (descrever a conduta em relação às pacientes que 
ISSN 1983-5183

não retornavam para as consultas do pré-natal na unidade, bem como a orientação fornecida às gestantes com quadro de SHG); c) Bloco do conhecimento - questões 07, 08, 09, 13 e 14 (foram relacionadas algumas doenças como: Hipertensão Gestacional (sem proteinúria), Pré-eclâmpsia/eclâmpsia, Pré-eclâmpsia sobreposta à hipertensão crônica e Hipertensão crônica, classificadas como SHG); d) Referência e contrareferência - questão 11 (dificuldades encontradas no encaminhamento das gestantes com quadro de SHG).

Os questionários foram entregues aos profissionais durante o período de trabalho nas unidades de saúde. Após o preenchimento, os participantes eram instruídos a colocar o questionário em um envelope sem identificação, lacrar e devolver de imediato para o pesquisador. A pesquisa ocorreu durante o período de 30 dias, sendo 2 visitas para cada unidade de saúde.

Os dados foram tabulados e analisados por meio de tabelas de distribuição de frequências absolutas e relativas.

\section{RESULTADOS}

A maioria dos participantes eram do sexo feminino $80 \%$ (20), com mais de quatro anos de formação 83,4\% (19), trabalhavam na Estratégia de Saúde da Família 76\% (20) e possuíam especialização 84\% (21), sendo que a área de saúde pública predominou com 32\% (8) da amostra (Tabela 1).

Tabela 01 - Perfil dos enfermeiros da estratégia de saúde da família que participaram da pesquisa, Guanambi, 2016.

\begin{tabular}{llcc}
\hline \hline Variável & Categoria & Frequência Absoluta & Frequência Relativa (\%) \\
\hline Gênero & Masculino & 5 & 20,0 \\
Tempo de Graduação & Feminino & 20 & 80,0 \\
& $1-2$ anos & 1 & 4,2 \\
& $2-4$ anos & 3 & 12,5 \\
Trabalha na ESF & $4-6$ anos & 10 & 41,7 \\
\multirow{5}{*}{ Especialização } & $6-8$ anos & 6 & 25,0 \\
& $>10$ anos & 4 & 16,7 \\
Área de Especialização & Sim & 19 & 76,0 \\
& Não & 6 & 24,0 \\
& Sim & 21 & 84,0 \\
& Não & 4 & 16,0 \\
& Emergências & 6 & 24,0 \\
& Saúde Pública & 8 & 32,0 \\
& Enfermagem do trabalho & 2 & 8,0 \\
& Saúde Coletiva & 2 & 8,0 \\
& Obstetrícia & 1 & 4,0 \\
& Saúde da Família & 3 & 12,0 \\
& Saúde Mental & 1 & 4,0 \\
\hline \hline
\end{tabular}

Fonte: Autoria própria.

O tempo de atuação na Estratégia de Saúde da Família variou de 01 mês a 09 anos. A variação de tempo em média que os enfermeiros ou técnicos deixaram de atuar na Estratégia de Saúde da Família (ESF) foi de no mínimo 01 mês e máximo de 04 anos. 
ISSN 1983-5183

Durante os 12 meses de pesquisa, foram identificadas 08 gestantes que estavam em acompanhamento com Síndromes Hipertensivas da Gravidez (SHG); dentre estas, 06 tiveram acompanhamento apenas na atenção secundária.

Sobre o conhecimento dos enfermeiros da Estratégia de Saúde da Família perante as SHG (Tabela 2), 64\% (16) dos participantes afirmaram que todas as gestantes da sua Unidade de Saúde continuam com as consultas de pré-natal, 03 (12\%) relataram que a maioria das gestantes continuam com atendimento na unidade de referência e 06 (24\%) afirmaram que nenhuma das gestantes permaneceu com acompanhamento na Estratégia de Saúde da Família, sendo um dos motivos a falta de orientação da equipe e realização da busca ativa.

Tabela 02 - Distribuição de frequências das questões sobre o conhecimento dos enfermeiros da Estratégia de Saúde da Família perante as Síndromes Hipertensivas da Gravidez.

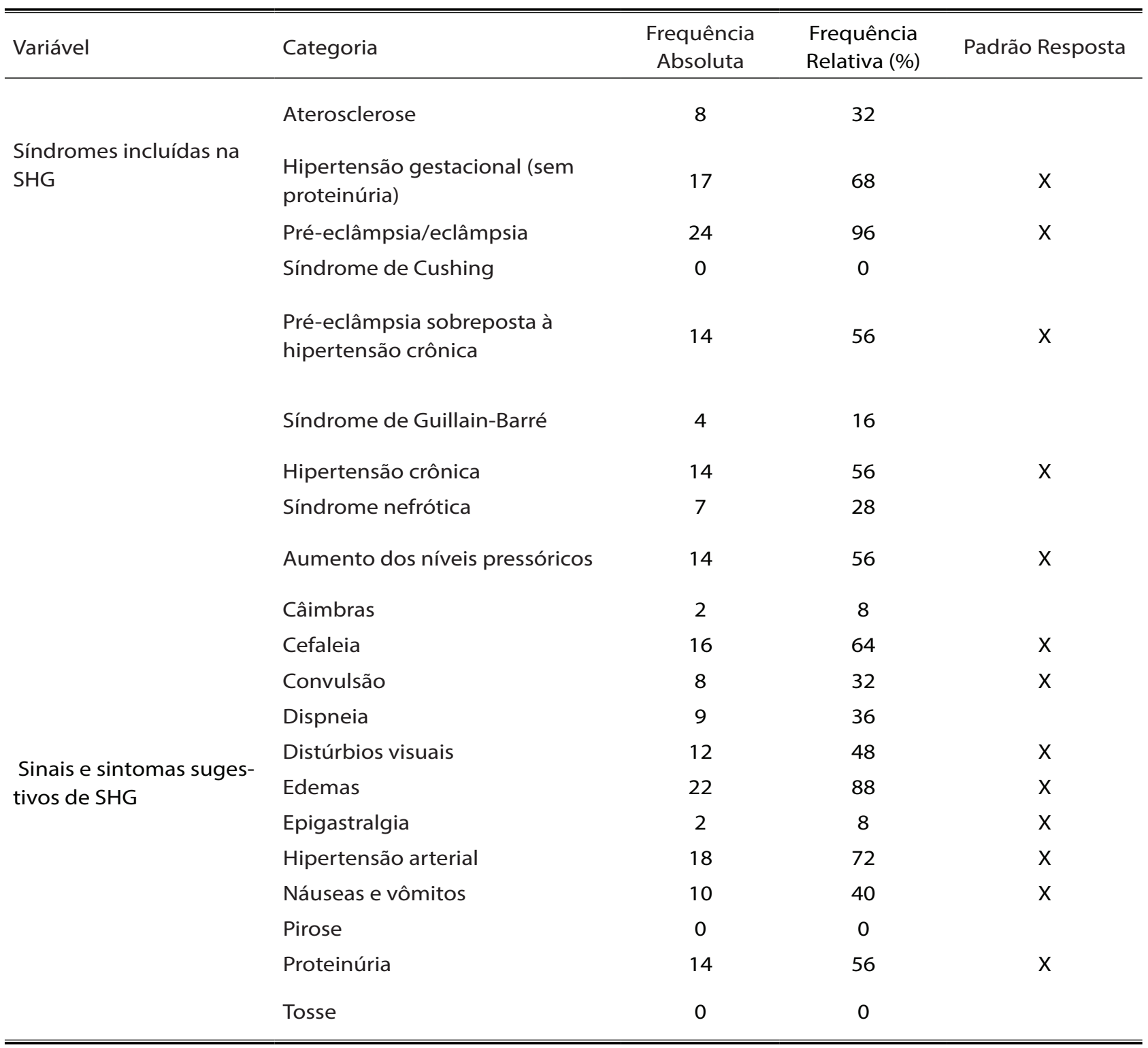




\begin{tabular}{llccc}
\hline \hline Variável & Categoria & $\begin{array}{c}\text { Frequência } \\
\text { Absoluta }\end{array}$ & $\begin{array}{c}\text { Frequência } \\
\text { Relativa (\%) }\end{array}$ & Padrão Resposta \\
\hline & Antecipação do parto & 20 & 80 & $\mathrm{X}$ \\
& Eclâmpsia & 20 & 80 & $\mathrm{X}$ \\
\cline { 2 - 3 } & Mortalidade materna e perinatal & 20 & 80 & $\mathrm{X}$ \\
Complicações e Conse- & & & \\
& Baixo peso ao nascimento & 13 & 52 & $\mathrm{X}$ \\
& Hiperemese gravídica & 0 & 0 & \\
& Colestase obstétrica & 0 & 0 & $\mathrm{X}$ \\
& Risco de prematuridade & 12 & 48 & $\mathrm{X}$ \\
& Estilo de vida & 22 & 88 & $\mathrm{X}$ \\
& Histórico familiar & 23 & 92 & $\mathrm{X}$ \\
Fatores de risco & Idade materna avançada & 21 & 84 & $\mathrm{X}$ \\
& Obesidade & 15 & 60 & $\mathrm{X}$ \\
& Baixa escolaridade & 3 & 12 & $\mathrm{X}$ \\
& Baixa renda familiar & 2 & 8 & $\mathrm{X}$ \\
\hline
\end{tabular}

Fonte: Autoria própria.

Embora 84\% relatassem ter especialização, apenas 44\% informaram ter recebido capacitação para o atendimento a gestantes com algum tipo de síndrome. Ao serem questionados sobre as SHG, 96\% dos entrevistados apontaram a pré-eclâmpsia e eclâmpsia, 68\% assinalaram hipertensão gestacional (sem proteinúria) e 56\% apontaram a pré-eclâmpsia sobreposta à hipertensão crônica e também relataram a hipertensão crônica. Já para os sinais e sintomas das síndromes, os participantes relataram edemas nos membros inferiores (88\%), 72\% hipertensão arterial, e 64\% da amostra apontaram a cefaleia como sendo um dos principais sintomas da SHG.

Referente às complicações e consequências mais citadas da SHG, 80\% (20) dos participantes relataram a antecipação do parto, eclâmpsia, mortalidade materna e perinatal como sendo as mais prevalentes. Os fatores mais assinalados como risco para as SHG foram o histórico familiar 92\% (23), o estilo de vida 88\% (22) e a idade avançada $84 \%$ (21).

A Tabela 3 descreve os resultados para as questões sobre a conduta dos enfermeiros da Estratégia de Saúde da Família perante a SHG, e todos os participantes (100\%) relataram a adesão das gestantes ao tratamento e frequência às consultas de pré-natal, $44 \%$ relatam dificuldades ao encaminhar gestantes com quadro de Síndromes Hipertensivas da Gravidez (SHG), 52\% informaram a deficiência no número de vagas oferecidas pelas unidades de atendimento, 12\% a demora na regulação e marcação para retorno. 
NASCIMENTO EFG, OLIVEIRA AMG, FLÓRIO FM, ZANIN L. Conhecimento e condutas realizadas por enfermeiros da atenção básica perante as síndromes hipertensivas da gravidez - SHG. Rev. Odontol. Univ. Cid. São Paulo 2019 jan-mar; 31(1): 6-16

ISSN 1983-5183

Tabela 03 - Distribuição de frequências das questões sobre a conduta dos enfermeiros da Estratégia de Saúde da Família perante as Síndromes Hipertensivas da Gravidez - SHG, Guanambi, 2016.

\begin{tabular}{llcc}
\hline \hline Variável & Categoria & Frequência & $(\%)$ \\
\hline Orientação & Aderir ao tratamento proposto & 25 & 100,0 \\
Necessária & Frequentar as consultas de pré-natal & 25 & 100,0 \\
& Realizar atividade física & 7 & 28,0 \\
& Acompanhamento exclusivo atenção secundária & 4 & 16,0 \\
& Alimentação deve ser balanceada & 17 & 68,0 \\
Teve dificuldade & Sim & 11 & 44,0 \\
Quais & Número de vagas oferecidas & 13 & 52,0 \\
Dificuldade & Não existe serviço de referência e contra referência & 0 & 0,0 \\
& Aderência da gestante às consultas & 0 & 0,0 \\
& A UBS não atende gestantes de alto risco risco & 1 & 4,0 \\
\hline \hline
\end{tabular}

Fonte: Autoria própria.

\section{DISCUSSÃO}

Com o acompanhamento da gestante pela equipe multiprofissional a possibilidade de serem identificados casos de SHG precocemente é maior tornando possível a prevenção bem como impedir o agravamento dos casos, sendo importantes as orientações e acompanhamentos adequados.

É importante para a gestante o acompanhamento por profissionais capacitados desde o início do período gestacional, sendo fundamental destacar a necessidade de a mulher realizar, no mínimo, seis consultas, a fim de que o enfermeiro e a equipe médica possam identificar os sinais, os sintomas e consequentemente prestar assistência adequada, tendo-se em vista que a ação do profissional de enfermagem é essencial para que possa cuidar, orientar, supervisionar e encaminhar a gestante a outros profissionais caso seja necessário ${ }^{\text {. }}$

Ao se analisarem os componentes do programa do Ministério da Saúde Rede Cegonha e os resultados das pesquisas de Lima et al. ${ }^{8}$ (2010), Lowdermilk et al. ${ }^{9}$ (2002) e Gardenghi e Gomes ${ }^{10}$ (2016), percebe-se a importância de os profissionais buscarem aperfeiçoamento, a fim de proporcionarem às gestantes atendimento com qualidade, tendo-se em vista a possibilidade de apresentarem algum tipo de problema associado às Síndromes Hipertensivas da Gravidez. Dados estes reforçados por esta pesquisa, quando relata o número de participantes com especialização. Esse é um momento especial e delicado em que a mulher se encontra necessitando de atenção, cuidados especiais e consequentemente um período gestacional saudável, sendo necessária uma equipe acolhedora e humanizada para o atendimento.

Destaca-se, como uma das razões do grande número de morte materna, a associação ao número insuficiente de instituições com assistência de qualidade e profissionais habilitados a realizar procedimentos com qualidade. É fundamental que os profissionais de saúde se preocupem não apenas com a mortalidade em números, mas também atente-se às causas que levaram a esse desfecho. Diante dos resultados, sugerese a implantação de medidas eficazes para a redução de tal problema, corroborando os estudos de Queiroz ${ }^{11}$ (2014).

Ao serem avaliados sobre o conhecimento perante as Síndromes Hipertensivas da Gravidez, os enfermeiros apontaram a Hipertensão gestacional (sem proteinúria), eclâmpsia e pré-eclâmpsia sobreposta à hipertensão 
NASCIMENTO EFG, OLIVEIRA AMG, FLÓRIO FM, ZANIN L. Conhecimento e condutas realizadas por enfermeiros da atenção básica perante as síndromes hipertensivas da gravidez - SHG. Rev. Odontol. Univ. Cid. São Paulo 2019 jan-mar; 31(1): 6-16

ISSN 1983-5183

crônica e a hipertensão crônica como principais sintomas, porém apresentaram algumas dificuldades ao classificá-las, identificando como características da síndrome a aterosclerose, Síndrome de Guillain-Barré e síndrome nefrótica, resultado este considerado contraditório, já que a análise dos resultados aponta que, apesar da falta de aprimoramento dos profissionais, não houve influência nas respostas, uma vez que o número de acertos foram superiores aos erros. As câimbras são decorrentes da falta de equilíbrio entre os nutrientes e água no organismo, podendo levar à contração dolorosa dos músculos, sendo um sinal preocupante aos profissionais, que acompanham as gestantes em seu pré-natal. Os profissionais ao serem questionados sobre os sinais e sintomas da SHG informaram as câimbras e dispneia como tendo alguma associação, o que contradiz os estudos de Barroso et al. ${ }^{12}$ (2011) que afirmam não serem essas características semelhantes às Síndromes Hipertensivas da Gravidez, não devendo serem citadas. A dispneia, sintoma comum da insuficiência cardíaca'3 ${ }^{13}$ muitas vezes é relacionada a SHG, apontada nesta pesquisa por $36 \%$ dos profissionais.

O profissional responsável pelo atendimento no pré-natal deve possuir como qualidades: a competência (para conduzir o acompanhamento de maneira eficaz, identificando em tempo hábil os possíveis fatores de risco gestacionais); humanização (a fim de perceber as dificuldades e anseios da paciente, e explicá-los) e a dedicação (demonstrar empenho na realização das consultas), possibilitando dessa forma um atendimento eficiente às gestantes, minimizando as falhas no diagnóstico precoce às SHG ${ }^{14}$.

Nesta pesquisa, os profissionais apontaram o aumento dos níveis pressóricos, a cefaleia, convulsão, distúrbios visuais, edemas, epigastralgia, hipertensão arterial, náusea seguida de vômitos e proteinúria como sendo os sinais de acometimento da SHG na gestante. Em relação às complicações e consequências das Síndromes Hipertensivas da Gravidez, os profissionais apresentaram dificuldades ao classificá-las, não havendo uniformidade nos acertos das questões referentes ao conhecimento dos enfermeiros na identificação da SHG

É importante destacar que o estilo de vida, histórico familiar, idade materna avançada, obesidade, baixa escolaridade, baixa renda familiar e hipertensão arterial crônica são fatores de risco para Síndromes Hipertensivas da Gravidez (SHG)', reconhecidos também nesta pesquisa pelos entrevistados; porém, consideraram como risco preponderante a cefaleia constante, sintoma este que não se enquadra na SHG. Isso pode estar associado ao fato de a cefaleia ser uma das principais queixas no período da gestação devido à vasodilatação por ação do estrogênio e progesterona ${ }^{15}$.

A redução da mortalidade materna, decorrente do parto e puerpério até 42 dias, bem como a de abortos em decorrência de procedimentos inadequados, pode ser alcançada com o apoio do NASF ${ }^{16}$, propiciando o preparo dos enfermeiros que participam do pré-natal de gestantes cadastradas na ESF, no reconhecimento precoce das SHG. Nesta pesquisa poucos relataram participar de capacitações, porém isso não influenciou no número de acertos ao questionário. Lowdermilk et al. ${ }^{9}$ (2002) enfatizam a importância da pós-graduação para que os profissionais aprimorem seus conhecimentos e estejam habilitados a atender casos específicos e complexos.

A busca por aperfeiçoamento, a fim de proporcionar às gestantes melhor atendimento na prevenção das Síndromes Hipertensivas da Gravidez(SHG), éumanecessidade ${ }^{11}$. Nesteestudo, menos da metadedos participantes relataram ter feito alguma capacitação relacionada às Síndromes Hipertensivas da Gravidez, embora a maioria dos profissionais relatem possuir especialização, o que se considera um ponto positivo nos conhecimentos do profissional de enfermagem, resultado pontuado no número de acertos no questionário aplicado na pesquisa, 0 que vem afirmar a importância dos cursos de pós-graduação no aprimoramento profissional. 
ISSN 1983-5183

Aderir ao tratamento proposto, frequentar as consultas do pré-natal e alimentação balanceada são ações para as quais o enfermeiro deve orientar as gestantes com Síndromes Hipertensivas da Gravidez. Ao serem avaliados a respeito dessas condutas, todos responderam que as gestantes aderiam ao tratamento proposto, frequentavam as consultas de pré-natal e realizavam atividade física com acompanhamento exclusivo na atenção secundária, sendo orientadas sobre a alimentação balanceada nesse período distinto. Para melhorar os indicadores de mortalidade materna, é necessário ter profissionais habilitados, atenção à saúde desde o início do pré-natal, frequentar todas as consultas e qualidade no atendimento, detalhes estes apoiados pelos dados desta pesquisa".

Em relação à dificuldade para encaminhamento, o município em estudo conta apenas com uma unidade de referência de alto risco, dificultando assim o acolhimento da demanda para atendimento às gestantes, agravando dessa forma a qualidade do atendimento, dados estes encontrados no estudo de Lima et al..$^{8}$ (2010). Os fatores negativos relativos ao acompanhamento de gestantes com SHG são as dificuldades de acompanhar os casos, tendo-se em vista problemas que vão desde a marcação de consultas até $\mathrm{o}$ atendimentos das gestantes.

Percebe-se que os mesmos questionamentos aqui abordados também são contemplados em outros estudos $^{8,10,17}$, relatando a SHG como fator contribuinte para uma gestação de risco e mortalidade materna, e identificou-se uma grande carência no atendimento a mulheres com casos de Síndromes hipertensivas, o que pode contribuir para a compreensão das necessidades e ações que devem ser implementadas para melhorar o atendimento de gestantes acometidas da SHG.

Para o atendimento às gestantes de alto risco, é fundamental que o município amplie as unidades de referência e ofereça cursos de aperfeiçoamento em parceria com a equipe do NASF para realização de educação permanente, participação na criação do protocolo de atendimento a essas gestantes, habilitando o profissional da enfermagem a cuidar, orientar, supervisionar e encaminhar as gestantes para o tratamento ideal, padronizado pelo Manual do Ministério da Saúde no protocolo da SHG.

Considerou-se como limitação do presente estudo a participação de profissionais de apenas um município, o que inviabiliza extrapolar os dados para municípios do entorno, considerando-se a necessidade de ampliar esta pesquisa de forma a mostrar diferentes realidades dos profissionais em relação ao atendimento de gestantes.

Os resultados desta pesquisa fortalecem a importância da implantação e execução do projeto da Rede Cegonha ${ }^{18}$ no município em questão, visando garantir um atendimento de qualidade de forma humanizada conforme preconizado pelo SUS, para todas as gestantes, reduzindo dessa forma a mortalidade materna ${ }^{19}$ ocasionada pelas Síndromes Hipertensivas da Gravidez, bem como outras patologias que podem ser evitáveis através de um serviço de saúde de qualidade na esfera da atenção básica, realizando um pré-natal assistido.

\section{CONCLUSÃO}

A investigação permitiu evidenciar a necessidade de aprimoramento profissional por parte dos enfermeiros, que apresentaram dificuldades em identificar as complicações e consequências da SHG, havendo necessidade de educação permanente para a equipe envolvida no atendimento a gestantes, com ou sem risco de Síndromes Hipertensivas da Gravidez. 
ISSN 1983-5183

\section{REFERÊNCIAS}

1. BRASIL. Ministério da Saúde. Secretaria de Atenção à Saúde. Departamento de Ações Programáticas Estratégicas. Gestação de alto risco: manual técnico. Brasília: Ministério da Saúde; 2012. [Acesso em: 25 abr. 2019.]; Disponível em: http://bvsms.saude.gov.br/ bvs/publicacoes/manual_tecnico_gestacao_alto_risco.pdf.

2. ZANATELLI C, Doberstein C, Girardi JP, Posser J, Beck DGS. Síndromes hipertensivas na gestação: estratégias para a redução da mortalidade materna. Rev saúde integrada 2016 9(17):73-81.

3. PERAÇOLI JC, Parpinelli MA. Síndromes hipertensivas da gestação: identificação de casos graves. Rev Bras Ginecol Obstet 2005 27(10):627-34.

4. SOARES JCS, Cavalcante AL, Santos LGML, França AMB, Xavier Júnior AFS. Óbitos maternos por síndromes hipertensivas induzidas pela gravidez no Estado de Alagoas no período de 2008-2013. Ciências Biológicas e da Saúde 2015 maio;2(3):67-79.

5. MORTON PG, Fontaine DK, Hudak CM, Gallo BM. Cuidados críticos de enfermagem: uma abordagem holística. Rio de Janeiro: Guanabara Koogan; 2007.

6. ZUGAIB M. Zugaib obstetrícia. Barueri, SP: Manole; 2008.

7. CHAVES APB, Mesquita SKC, Ramos DKR. Doença hipertensiva específica da gestação: conduta de enfermeiros em unidade básica de saúde. Revista da Universidade Vale do Rio Verde 2014 jan./jul. ;12(1):648-54.

8. LIMA ÉMA, Paiva LF, Amorim RKFCC. Conhecimento e atitudes dos enfermeiros diante de gestantes com sintomas da Doença Hipertensiva Específica da Gestação (DHEG) atendidas em Unidades Básicas de Saúde (UBS). J Health Sci Inst 2010 28(2):151-3.

9. LOWDERMILK DL, Perry SE, Bobak IM. O cuidado em enfermagem materna. 5. ed. Porto Alegre: Artmed; 2002.

10. GOMES NR, Gardenghi G. Prevalência de complicações maternas e neonatais em gestações que apresentaram síndromes hipertensivas. RESC 2013 3(1):59-71.

11. QUEIROZ MR. Ocorrência das síndromes hipertensivas na gravidez e fatores associados na região sudeste do Brasil [Dissertação]. São Paulo: Universidade de São Paulo, Faculdade de Saúde Pública; 2014.

12. BARROSO GC, Thiele ES. Lesão muscular nos atletas. Rev bras ortop 2011 46(4):354-8.

13. MARTINEZ JAB, Padua Al, Terra Filho J. Dispnéia. Medicina, Ribeirão Preto 2004 jul./ dez.;37(1):199-207.

14. BUCHABQUI JA. Assistência pré-natal. In: Freitas, F. Rotinas em obstetrícia. 5. ed. Porto Alegre, RS: Artmed; 2006.

15. MURAZAWA MM, Nahime M, Giovanetti NM, Carvalho CMP. Cefaleia na gestação. Rev Fac Ciências Médicas de Sorocaba 2015 out.; 17(Supl.):

16. FITTIPALDI ALM, Romano VF, Barros DC. Nas entrelinhas do olhar: apoio matricial e os profissionais da estratégia saúde da família. Saúde debate 2015 39(104):76-87. 
ISSN 1983-5183

17. GONÇALVES R, Fernandes RAQ, Sobral DH. Prevalência da doença hipertensiva específica da gestação em hospital público de São Paulo. Rev bras enferm 2005 58(1):61-4.

18. BRASIL. Ministério da Saúde. Secretaria de Atenção à Saúde. Departamento de Ações Programáticas Estratégicas. Coordenação Geral de Saúde das Mulheres. Nota técnica: inserção da eletroforese de hemoglobina nos exames de pré-natal: Rede Cegonha. 2013. [Acesso em: 25 abr. 2019.]; Disponível em: https://www. mpba.mp.br/system/files_force/biblioteca/nt_035_2011_rede_cegonha_1.pdf?download=1.

19. SOUZA MAS, Lopes NAR, Borges FV. A importância do enfermeiro da estratégia saúde da família para a redução da morbimortalidade materna. Revista Científica Interdisciplinar 2014 1(1):

RECEBIDO EM 29/01/2018

ACEITO EM 21/01/2019 